\title{
Effects of Organizational Justice of Civil Servants From the Perspective of Workplace Spirituality
}

\author{
Jianglin $\mathrm{Ke}^{1}$, Chen Chen ${ }^{1}$ and Yuan Zeng ${ }^{1, *}$

\begin{abstract}
${ }^{1}$ School of Government, Beijing Normal University, Beijing, 100875, China
\end{abstract} \\ *Corresponding author. Email: bnu_zengy@163.com
}

\begin{abstract}
Creating a clear and fair organization climate is very important for the government. In order to find out the influence of organizational justice, this study adopted a new view of workplace spirituality and examined the influence of civil servants organizational justice on their work engagement, job satisfaction and job performance. This study used 321 civil servants as a sample for empirical research. Through questionnaire survey, using Structural Equation Modelling (SEM) for data analysis, the results show that organizational justice plays a positive role on civil servants' work engagement, job satisfaction and job performance, and workplace spirituality fully mediates their relationship. The results of the study generally indicate that civil servants have high expectations for the organization, and the government departments should take more measures to create a fair environment for them to enhance workplace spirituality and work results. Keywords: organizational Justice, workplace Spirituality, work Engagement, job Satisfaction, job
\end{abstract}

performance

\section{INTRODUCTION}

Creating a clear and fair organization climate is very important for the government. A good organizational climate allows employees to define organizational expectations, locate their roles, and ultimately help organizations improve their performance and achieve their goals. The fair and equitable organizational climate has positive significance. Empirical research has found that employees' sense of organizational justice has a positive effect on their work engagement, turnover intention, organizational citizenship behavior, organizational trust, organizational commitment, and organizational performance. But these findings are mainly from corporate organizations. Equity systems and procedures make it difficult for civil servants to obtain power-seeking opportunities of public power. Whether the positive effects of organizational justice exist in government organizations still needs to be tested. In addition, previous studies mainly used organizational commitment, organizational identification, organizational support, and psychological safety as mediator variables to explain the impact of organizational justice [1]. It's not appropriate to simply transplant the original theory and research results into civil servants. Organizational justice may provoke a higher level of spiritual power than ordinary emotions. Civil servants pay more attention to self-transcendence and higher public service motivation than ordinary corporate employees [2]. Workplace spirituality, which can reflect the satisfaction of high-level individual spiritual needs, is adopted as the mediator variable to explain the influence mechanism of organizational justice in government departments. It will be a new research perspective and worthy to explore.
Moreover, it can also respond to the call of many scholars to strengthen the frontier research on workplace Spirituality of civil servants or public sector personnel [3].

\section{LITERATURE AND HYPOTHESIS}

\subsection{Organizational justice and job satisfaction, work engagement and job performance}

Job satisfaction and work engagement are two important attitude variables commonly used in organizational behavior research. Job performance is an important outcome measure in studies in the workplace. According to equity theory (Adams, 1965), Human motivation is influenced by the comparison between their input and output and the input and output of others. When employees feel that they are being treated unfairly in the workplace, they will change behaviors, attitudes or change both to restore justice. For example, if employees perceive that work compensation is unfair relative to work engagement, it can cause tension and may ultimately reduce work engagement, job satisfaction and job performance [4]. In addition, when organizational justice is at a low level, it is highly prone to the situation that work requirements are higher than work resources. Contribution-oriented contractual relationships cause them to resist change, negative work, and tend to leave. While when organizational justice is at a high level, work Requirements are lower than the working resources, the incentiveoriented psychological contract makes them more supportive to change, active work, and increase work 
engagement, job satisfaction and job performance. Therefore, the study proposes the following hypotheses:

Hla: Organizational justice of civil servants has a positive effect on their job satisfaction.

H1b: Organizational justice of civil servants has a positive effect on their work engagement.

H1c: Organizational justice of civil servants has a positive effect on their job performance.

\subsection{Workplace spirituality and Job satisfaction, work engagement and Job performance}

Workplace spirituality is mainly reflected in purpose in one's work or "meaningful work"(individual level), having a "sense of community"(group level), and being in "alignment with the organization's values" and mission(organization level). These three core dimensions are closely related to job satisfaction, work engagement and Job performance. According to the job characteristics model (Hackman and Oldham, 1976) and the intrinsic motivation theory ( Deci and Ryan, 1980), meaningful work is conducive to employees to generate intrinsic motivation, improve work engagement, occupational wellbeing and job satisfaction, and reduce job burnout. In addition, self-determination theory believes that when employees meet their autonomy needs, ability needs, and belonging needs, they will have higher internal satisfaction and work motivation [5]. Employees with a high sense of community are satisfied with their work because they are satisfied with their belonging needs. Alignment with the organization's values is reflected in the recognition of organizational culture. According to Organizational Identification theory (Tajfel, 1978), employees with a high sense of alignment with the organization's values will have a high sense of organizational trust and support, further high job satisfaction, work engagement and Job performance. Therefore, the study proposes the following hypotheses:

H2a: Workplace spirituality of civil servants has a positive effect on their job satisfaction.

$H 2 b$ : Workplace spirituality of civil servants has a positive effect on their work engagement.

H2c: Workplace spirituality of civil servants has a positive effect on their job performance.

\subsection{The Mediation Role of Workplace Spirituality}

From the perspective of workplace spirituality, the values contained in organizational justice are easily recognized by the public, and organizational justice is easy to form a harmonious relationship, which is conducive to enhancing the sense of community of employees. In addition, personal values are easily realized and recognized in a fair organizational climate, so that individuals have a higher sense of meaningful work. Workplace spirituality is essentially a positive psychological resource formed by individuals after self-transcendence. The Conservation of Resource Theory (COR, Hobfoll, 1989) believes that individuals with more personal resources are not only less vulnerable to resource losses, but also more capable of acquiring new resources, so that they have less stress and burnout, showing more positive spiritual states and behaviors [6]. COR theory divides resources into four categories: material resources, conditional resources, selfresources and energy resources. Workplace spirituality belongs to self-resources. According to the COR theory, the positive psychological resources of the civil servants obtained from the fair organization environment contribute to the enhancement of work engagement and job satisfaction and the improvement of job performance. Therefore, the study proposes the following hypotheses:

H3a: Organizational justice of civil servants has a positive effect on their workplace spirituality.

H3b: Workplace spirituality of civil servants mediates the relationship between organizational justice and job satisfaction, work engagement and job performance.

\section{METHOD}

\subsection{Sample}

In order to ensure the rigor of the study, two rounds of questionnaires were used. A total of 430 questionnaires were distributed, 389 questionnaires were returned, and 321 questionnaires were valid, with a recovery rate of $90.5 \%$ and a valid rate of $74.7 \%$. Among them, 116 were males $(36.1 \%)$, and 205 were females $(63.9 \%)$. The age distribution of the questionnaire results is relatively average: $20-30$ years $(33.6 \%), 30-40$ years $(30.5 \%), 40-50$ years $(27.7 \%),>50$ years $(8.1 \%)$. The working years distribution is as following: <10 years (46.7\%), $10-20$ years $(18.4 \%), 20-30$ years $(28.3 \%),>30$ years $(6.5 \%)$.

\subsection{Measures}

Organizational justice. We used Greenberg and Colquitt's (2005) perceived pay equity, Yan Ge's (2005) civil servant's promotion justice scale and Zhang Yongjun (2012) civil servant's performance appraisal justice scale [7-9]. After the partial adjustment of the item, there are 15 items. In this study, the Cronbach's Alpha was 0.910.

Work engagement. We used the Work Engagement Scale (UWES, 2006) [10]. The scale language is appropriately adjusted to better suit the China mainland context. There are 5 items. In this study, the Cronbach's Alpha was 0.894 . Job Satisfaction. We used the Minnesota Satisfaction Scale (MSQ, 1967) [11]. There are 5 items. In this study, the Cronbach's Alpha was 0.805 .

Job Performance. We used Liao Jianqiao and Han Yi's (2007) Job Performance Scale [12]. There are 5 items. In this study, the Cronbach's Alpha was 0.901 . 
Workplace spirituality. We used Ke Jianglin's (2014) workplace spirituality Scale [13]. There are three core dimensions: meaningful work, sense of community and alignment with the organization's values. Each dimension has 9 items. In this study, the Cronbach's Alpha was 0.912. All substantive variables were assessed using a Likert-type scale ( $1=$ strongly disagree, $5=$ strongly agree).

\subsection{Common Method Biases Test}

In order to reduce the common variance, the questionnaire indicates that the study is anonymous investigation and there is no right or wrong for the answer, so that the participants can answer it honestly. Meanwhile, the Harman single factor test was used to verify the degree of common variance of each study variable. The results showed that 7 factors explained $69.31 \%$ of the total variation, and factor 1 explained $32.87 \%$. There was no single factor explaining most of the variation, indicating that the common variance of the study data was not serious.

\section{RESULTS ANALYSIS}

\subsection{Descriptive Statistics and Correlations}

Table 1 presents descriptive statistics and correlations. Organizational justice, workplace spirituality, work engagement, job satisfaction, job performance of civil servants are all significantly related. Hypothesis 1-2 are initially supported, and the results lay the foundation for hypothesis 3 .
Table 1 Descriptive statistics and correlations $(\mathrm{N}=321)$

\begin{tabular}{|c|c|c|c|c|c|c|}
\hline & $\mathrm{M}$ & $\mathrm{SD}$ & 1 & 2 & 3 & 4 \\
\hline 1 & 3.422 & .866 & & & & \\
\hline 2 & 3.418 & .841 & $.708 * *$ & & & \\
\hline 3 & 3.297 & .799 & $.691 * *$ & $.756 * *$ & & \\
\hline 4 & 3.866 & .848 & $.661 * *$ & $.574 * *$ & $.552 * *$ & \\
\hline 5 & 3.748 & .781 & $.725 * *$ & $.747 * *$ & $.776 * *$ & $.545 * *$ \\
\hline
\end{tabular}

(1.Organizational Justice, 2.Work Engagement, 3.Job Satisfaction, 4.Job Performance, 5.Workplace Spirituality)

\subsection{Structural Equation Modeling Fitting Test}

In order to test and compare the relationships between variables, the basic model and three alternative models are set. The basic model is a full mediation model based on the null hypothesis; the alternative model 1 is a partial mediation model; the organizational justice and workplace spirituality are all independent variables in the alternative model 2, and job satisfaction, work engagement and job performance are dependent variables, and to examine the possibility of non-mediating role of workplace spirituality; the order of workplace spirituality and organizational justice is exchanged in alternative model 3 , and to examine whether individuals with strong workplace spirituality can feel organizational justice and have better work results. The above four models form a nested model that allows for fitting comparisons. Before using the Amos to test the structural equation modeling, considering the situation of too many original survey items, the questionnaire survey items were packaged according to the exploratory analysis results, and after packaging, the number of items of organization justice, workplace spirituality, work engagement, job satisfaction and job performance are all three. The fitting results of the four models are shown in Table 2.

Table 2 Model Fitting Table

\begin{tabular}{|c|c|c|c|c|c|c|c|c|}
\hline Model & $\chi^{2}$ & $\mathrm{df}$ & $\chi^{2}$ df & GFI & AGFI & CFI & RMESA & NNFI \\
\hline Basic model & 334.35 & 100 & 3.34 & .887 & .843 & .930 & .091 & .907 \\
\hline Alternative model 1 & 329.75 & 97 & 3.40 & .903 & .861 & .951 & .087 & .938 \\
\hline Alternative model 2 & 403.08 & 98 & 4.13 & .835 & .771 & .893 & .093 & .871 \\
\hline Alternative model 3 & 361.82 & 97 & 3.73 & .866 & .812 & .930 & .092 & .913 \\
\hline
\end{tabular}

It can be seen from the results of Table 2 that the fitting of the alternative models 2 and 3 is significantly inferior to the basic model, and the degrees of freedom are smaller than the basic model. In addition, although the fitting model 1 is better than the basic model, it does not reach a significant difference $(\Delta \chi 2(3)=4.6, \mathrm{p}>0.05)$. According to the simplicity principle of the model, the basic model is a better one than the alternative model 1. Therefore, workplace spirituality fully mediated the relationship between organizational justice and job satisfaction, work engagement and job performance. Fig. 1 shows the coefficient between the variables in the basic model, which indicates that the research hypotheses in this study are supported. 


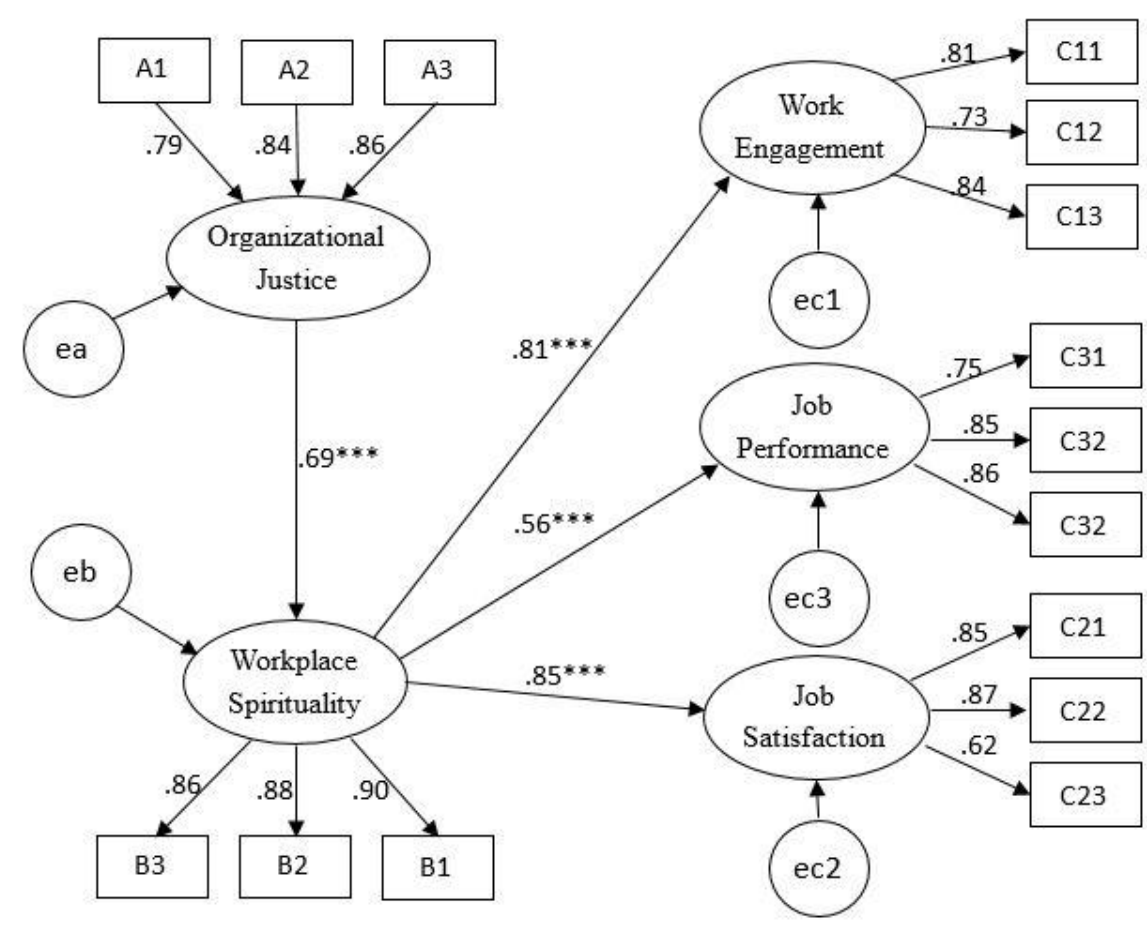

Figure 1. Workplace Spirituality's full mediation model of the relationship between Organizational Justice and Work Engagement, Job Satisfaction and Job Performance

Table 3 reports the effects of the various variables. First, organizational justice is significant and positively related to workplace spirituality $(\beta=0.691, \mathrm{p}<0.001)$. The correlations of workplace spirituality with job satisfaction, work engagement, and job performance were 0.852 ( $\mathrm{p}<$ $0.001), 0.814(\mathrm{p}<0.001)$, and $0.563(\mathrm{p}<0.001)$, respectively. The indirect impact of organizational justice on job satisfaction, work engagement and job performance through workplace spirituality (mediator) were $0.588(\mathrm{p}<$ $0.001), 0.561$ ( $\mathrm{p}<0.001$ ), and 0.388 ( $\mathrm{p}<0.001)$, respectively. In comparison, organizational justice and workplace spirituality have a greater impact on job satisfaction, and the least impact on job performance.

Table 3 Direct, indirect and overall effects of each variable

\begin{tabular}{|c|c|c|c|c|c|}
\hline \multicolumn{2}{|c|}{ Independent variables } & \multicolumn{4}{c|}{ Dependent variable } \\
\cline { 3 - 6 } \multicolumn{2}{|c|}{} & $\begin{array}{c}\text { Workplace } \\
\text { spirituality }\end{array}$ & $\begin{array}{c}\text { Work } \\
\text { engagement }\end{array}$ & $\begin{array}{c}\text { Job } \\
\text { satisfaction }\end{array}$ & $\begin{array}{c}\text { Job } \\
\text { performance }\end{array}$ \\
\hline \multirow{2}{*}{$\begin{array}{c}\text { Organizational } \\
\text { justice }\end{array}$} & Overall effect & $0.691 * * *$ & $0.561 * * *$ & $0.588^{* * *}$ & $0.388^{* * *}$ \\
\cline { 2 - 6 } & Indirect effect & - & $0.561 * * *$ & $0.588^{* * *}$ & $0.388^{* * *}$ \\
\cline { 2 - 6 } & Direct effect & $0.691 * * *$ & - & - & - \\
\hline \multirow{2}{*}{$\begin{array}{c}\text { Workplace } \\
\text { spirituality }\end{array}$} & Overall effect & - & $0.814 * * *$ & $0.852^{* * *}$ & $0.563 * * *$ \\
\cline { 2 - 6 } & Indirect effect & - & - & - & - \\
\cline { 2 - 6 } & Direct effect & - & $0.814 * * *$ & $0.852^{* * *}$ & $0.563^{* * *}$ \\
\hline
\end{tabular}

\section{CONCLUSION AND SUGGESTION}

First, organizational justice of civil servants has a significant and positively correlation on job satisfaction, work engagement and job performance. The descriptive statistics of this paper find that civil servants have poor work enthusiasm, low work engagement and low work efficiency. How to improve work attitude and performance of the civil servants is an urgent problem to be solved. The empirical analysis of this study found that creating a clear and fair organization climate by anti-corruption is an effective way to solve the situation that civil servants are neglectful of their duties.

Second, workplace spirituality is significant and positively related to civil servants' work attitude and performance. This study found that work spirituality of the civil servants are highly correlated with their work attitude and results. It proves that the civil service group cares more about 
internal spiritual satisfaction, pays more attention to the meaningful work, sense of community, alignment with the organization's values, and shows that public organizations are closely related to the workplace spirituality [3]. The results of this study provide new ideas on how government agencies effectively inspire civil servants.

Third, workplace spirituality plays a fully mediating role in the relationship between organizational justice and work engagement, job satisfaction and job performance. As a self-reactive psychological resource, according to conservation of resource theory [6], civil servants will obtain such positive psychological resources from a justice organizational environment, which will contribute to the enhancement of work engagement and the improvement of job performance. At the same time, according to personenvironment theory, civil servants who pursue selftranscendence and desire for spiritual needs have more ardent expectations and recognitions for the moral standards and values of organizational justice, and it is easier to breed high workplace spirituality and produce good work attitudes and results. This study confirms this hypothesis and finds that the civil servant's workplace spirituality fully mediates the relationship between organizational justice and job satisfaction, work engagement, and job performance. This result provides a new perspective for us to fully understand the impact mechanism of organizational justice.

The research results have the following implications for government management. (1) The results of the study show that the level of work engagement and job performance of civil servants are only in a medium position, and job satisfaction is even lower. Government departments should analyze the reasons for the inaction of some civil servants, and try their best to improve job satisfaction and job performance of civil servants. (2) The results of this study indicate that workplace spirituality has cross-organizational effectiveness and has a positive effect on civil servant job satisfaction, work engagement and job performance. The government should comprehensively use human resources management practices, leadership styles, organizational climate and other means to enhance civil servants' workplace spirituality, so that it can experience the meaning of work, the sense of community and organizational culture and values. (3) The results of this study show that organizational justice contributes to the formation of civil servants' workplace spirituality and further promotes their job satisfaction, work engagement and job performance. Therefore, government departments should overcome the relationship of human relations in performance appraisal, promotion, salary distribution, etc., and strengthen the construction of the justice system and procedures.

\section{REFERENCES}

[1] X. Lyu, "Effect of organizational justice on work engagement with psychological safety as a mediator: Evidence from China," Social Behavior and Personality: An International Journal, vol. 44, No. 8, pp. 1359-1370,
2016. DOI:

http://dx.doi.org/10.2224/sbp.2016.44.8.1359

[2] Y. Han, "Is public service motivation changeable? integrative modeling with goal-setting theory," International Journal of Public Administration, vol. 41, No. 3, pp. 216-225, 2018. DOI: http://dx.doi.org/10.1080/01900692.2016.1262871

[3] D. J. Houston, and K. E. Cartwright, "Spirituality and public service," Public Administration Review, vol. 67, No. 1, pp. 88-102, 2007. DOI: http://dx.doi.org/10.1111/j.1540-6210.2006.00699.x

[4] M. Fiaz, A. Ikram, Q. Su, and N. Ali, "How to save the saviors? Relationship between organizational justice and citizenship behavior," The Journal of Developing Areas, vol. 52, No. 1, pp. 45-58, 2018. Retrieved from https://search.proquest.com/docview/1960277627?acco untid $=8554$

[5] R. M. Ryan, and E. L. Deci, "Intrinsic and extrinsic motivations: Classic definitions and new directions," Contemporary Educational Psychology, vol. 25, No. 1, pp. 54-67, 2000. DOI:

http://dx.doi.org/10.1006/ceps.1999.1020

[6] S. E. Hobfoll, "Conservation of resources: A new attempt at conceptualizing stress," American Psychologist, vol. 44, No. 3, pp. 513-524, 1989. DOI: http://dx.doi.org/10.1037/0003-066X.44.3.513

[7] J. Greenberg, and J. Colquitt, Handbook of organizational justice, New Jersey: Lawrence Erlbaum Associates Publishers, Mahwah, 2005, pp. 32-47. Retrieved from https://search.proquest.com/docview/620723884?accou ntid $=8554$

[8] G. Yan, “A Study on Promoting Justice of Government Official and Its Relationship with Organizational Politics," Henan University (People's Republic of China), 2011. (In Chinese) Retrieved from https://kns.cnki.net/KCMS/detail/detail.aspx?dbname=C MFD0506\&filename=2005095666.nh

[9] Y. J. Zhang, "Research on the Influence Mechanism of Fairness Perceptions in Performance Appraisal on Counterproductive Work Behavior," Huazhong University of Science and Technology (People's Republic of China), 2012. (In Chinese) Retrieved from https://kns.cnki.net/KCMS/detail/detail.aspx?dbname $=\mathrm{C}$ DFD1214\&filename $=1012361157 . \mathrm{nh}$

[10] W. B. Schaufeli, A. B. Bakker, and M. SalaNova, "The measurement of work engagement with a short 
questionnaire: A cross-national study. Educational and Psychological Measurement," vol. 66, No. 4, pp. 701716, 2006. DOI:

http://dx.doi.org/10.1177/0013164405282471

[11] D. J. Weiss, R. V. Dawis, and G. W. England, "Manual for the Minnesota satisfaction questionnaire," Minnesota Studies in Vocational Rehabilitation, vol. 22, p. 120, 1967. Retrieved from https://search.proquest.com/docview/615528339?accou ntid $=8554$

[12] Y. Han, J. Q. Liao, and L. R. Long, "Model of development and empirical study on employee job performance construct," Journal of Management Sciences in China, vol. 5, pp. 62-77, 2007. (In Chinese) Retrieved from

https://kns.cnki.net/kcms/detail/detail.aspx?FileName=J CYJ200705006\&DbName=CJFQ2007

[13] J. L. Ke, J. M. Sun, J. Wang, "Development and Validation of the Workplace Spirituality Scale," Chinese Journal of Clinical Psychology, vol. 5, pp. 826830, 2014. (In Chinese) DOI: 10.16128/j.cnki.10053611.2014.05.060. 